Trab. Ling. Aplic., Campinas, 45(1): 29-54, Jan./Jun. 2006

\title{
O PROFESSOR DE INGLÊS E O LIVRO DIDÁTICO: QUE RELAÇÃO É ESSA?
}

\author{
ROSELY PEREZ XAVIER \\ Universidade Federal de Santa Catarina \\ EVERLAINE DALUZ WEBER URIO \\ Escola de Educação Básica Paulo Schieffler
}

\begin{abstract}
RESUMO
Este artigo discute a relação que os professores de inglês de escolas básicas e de idiomas estabelecem com o livro didático e o manual de ensino, bem como seus critérios de seleção e avaliação desses materiais. O estudo contou com a participação de 30 professores da cidade de Caçador, SC, que responderam a um questionário, possibilitando investigar o nível de influência desses recursos no seu ensino. Os dados apontam relações de maior ou menor rigidez, dependendo do contexto educacional. Os critérios de seleção e avaliação envolvem o conteúdo de ensino, os exercícios, os textos, a gramática e o layout do livro didático.
\end{abstract}

Palavras-chave: livro didático de inglês; influências no fazer docente; seleção e avaliação de livro didático.

\begin{abstract}
This paper discusses the relationship that Brazilian teachers of English from basic schools and private language courses establish with the English textbook and the teacher's manual, as well as their criteria for textbook selection and evaluation. 30 teachers from Caçador, SC answered a questionnaire which enabled the researchers to investigate the level of influence of these resources on their practice. The data show more or less flexibility in this relationship depending on the educational context. The criteria for textbook selection and evaluation involve the instructional content, the exercises, the texts, the grammar and the layout.
\end{abstract}

Key-words: english textbook; influences on teaching practice; textbook selection and evaluation.

\section{CONHECENDO O OBJETO DE ESTUDO}

O mercado nacional conta com uma rica variedade de materiais pedagógicos de língua estrangeira que podem ser utilizados pelo professor e/ou alunos. São livros didáticos, paradidáticos, dicionários, revistas, enciclopédias, jogos educativos e outros, cuja escolha vai depender do professor, conforme seus objetivos de ensino e as necessidades e interesses dos alunos. Dentre esses materiais, pode-se dizer que o livro didático é o que influencia sobremaneira as decisões didático-pedagógicas do professor.

Muitos professores preferem adotar um livro didático para facilitar e agilizar o processo de ensino e aprendizagem. Dependendo da escola, a sua escolha é feita pelo professor, como em muitos contextos públicos do ensino fundamental e médio. Em outras escolas, a 
XAVIER \& URIO - O professor de inglês e o livro didático: que relação é essa?

escolha do livro didático compete ao diretor ou coordenador pedagógico, como nas escolas de idiomas e em alguns contextos particulares do ensino básico, os quais adotam o sistema de apostilas.

Nas palavras de Demo (1993): "como o melhor livro didático é o professor, parece correta a expectativa de que ele escolha o(s) livro(s) que vai usar. Todavia, a capacidade de escolha supõe competência técnica considerável, a par do conhecimento do leque de ofertas" (p.109). Isso significa dizer que o professor precisa estar atualizado quanto aos novos títulos publicados e adotar critérios válidos para a avaliação dos materiais disponíveis no mercado, de modo a compará-los para a decisão final.

Por outro lado, há professores que, ao invés de adotar um livro didático, preferem utilizá-lo apenas como referencial no preparo de suas aulas sem segui-lo literalmente. Neste caso, um ou mais livros são consultados para organizar suas atividades de ensino. Há ainda professores que não recorrem aos livros didáticos como material norteador, preferem produzir suas próprias atividades com base em textos de revistas e jornais ou em outros materiais inspiradores que possam ter fins didáticos.

Embora considerados instrumentos importantes no auxílio do trabalho docente, os livros didáticos devem ser repensados e reavaliados, pois, por melhor que possam parecer, não atendem às demandas que emergem das necessidades de aprendizagem de cada contexto de ensino. Além disso, a elaboração desses materiais nem sempre é feita por profissionais experientes na área, que dominam questões lingüísticas e culturais, ou, ainda, que buscam oferecer uma metodologia voltada para a aprendizagem significativa, autônoma e potencializada.

Pensando na qualidade das informações do livro didático, o Ministério da Educação (MEC), através de seu Programa Nacional do Livro Didático (PNLD), vem elaborando, desde 1997, guias de livros didáticos, cujo objetivo maior é subsidiar os professores na escolha consciente e segura dos livros de $1^{\mathrm{a}}$ a $4^{\mathrm{a}}$ e de $5^{\mathrm{a}}$ a $8^{\mathrm{a}}$ séries do ensino fundamental nas seguintes áreas do conhecimento: Alfabetização, Língua Portuguesa, Matemática, Ciências, História e Geografia, além de dicionários da Língua Portuguesa. A língua estrangeira, em particular a Língua Inglesa, não parece ser uma área que preocupa os especialistas do MEC, pois até hoje nenhuma avaliação foi realizada envolvendo livros de língua estrangeira para a educação básica. Pode parecer que, na concepção do governo, esses livros pouco influenciam a formação da criança ou jovem ou, ainda, que os livros de língua estrangeira não são freqüentemente adotados nas escolas. Daí a sua isenção no processo avaliativo.

Paralelamente à qualidade do livro didático, existe a preocupação com a formação do professor, pois é ele quem dá vida a esse material, o responsável por didatizar o conteúdo apresentado, transformando-o em conhecimento. Para Faria (2000), além da importância de avaliar a qualidade e a relevância dos conteúdos, o professor deve saber desenvolvê-los com uma linguagem que se adeque às capacidades cognitivas e lingüísticas dos estudantes, além de fomentar sua reflexão, espírito crítico e criatividade.

Nesta perspectiva, pode-se dizer que o sucesso ou insucesso de uma aula ou curso não depende exclusivamente do livro didático ou de materiais complementares, mas das 
concepções dos professores sobre ensinar e aprender, que deverão nortear a sua metodologia. Com base em sua abordagem ${ }^{1}$, o professor pode subverter o livro didático ou segui-lo à risca, sem questioná-lo. Um material considerado "inovador", por exemplo, dependerá do professor para tornar essa característica possível em sala de aula. Nesse sentido, outros fatores, além do livro didático, concorrem para o bom andamento de uma aula/curso, como a maneira dos professores ensinarem, o tipo de interação que promovem em sala de aula, a motivação e interesse do professor e alunos, a relevância dos temas e das atividades propostas, entre outros.

Entende-se que o livro didático é imprescindível no âmbito escolar, mas dependerá da capacidade do professor de (re)interpretá-lo na prática pedagógica, podendo adaptar, complementar, retificar e suplementar o material, criando novas possibilidades para a aprendizagem dos alunos de acordo com suas reais necessidades.

\begin{abstract}
Todos os apoios didáticos, importantes entre si, dependem da capacidade do professor, inclusive do aproveitamento das adequações físicas dos estabelecimentos, do material escolar etc. O único livro didático insubstituível é o próprio professor. Deve estar de tal modo bem formado, que, se necessário for, ele mesmo prepara texto de português, exercício de matemática, projeto de planejamento etc. (Demo, 1993, p.89)
\end{abstract}

Considerando o livro didático um material regularmente presente na vida do professor de inglês, surgiu o nosso interesse em investigar essa relação, ou seja, até que ponto este material exerce influência no fazer desse professor e que possível relação de poder existe entre eles. Quem influencia quem na prática pedagógica? Qual é a confiança e credibilidade dispensada a este recurso? O que é um bom livro didático para os professores de inglês? E que critérios eles consideram importantes na escolha ou seleção desse material?

Partindo das percepções dos professores sobre a influência do livro didático em seu trabalho, propusemos fazer um panorama sobre essa relação num dado recorte contextual, podendo suscitar questões a serem discutidas mais amplamente em outros momentos. $\mathrm{O}$ objetivo deste estudo é, portanto, analisar o papel do livro didático no trabalho docente e os elementos que os professores consideram ao avaliar e selecionar este recurso. Especificamente, pretende-se (a) redimensionar a importância do livro didático na prática do professor; (b) fazer um levantamento sobre as informações que o mesmo procura ou usa em um livro didático e (c) conhecer seus critérios de seleção e avaliação.

\title{
A RELAÇÃO DO PROFESSOR DE INGLÊS COM O LIVRO DIDÁTICO
}

O livro didático de língua inglesa (como também das demais línguas estrangeiras) tem o poder de influenciar os professores no conteúdo a ser ensinado, nas atividades a

\footnotetext{
1 Abordagem “... é um conjunto de crenças, pressupostos e princípios sobre um conceito de língua, de ensinar e aprender uma língua estrangeira, uma espécie de filosofia, uma força potencial capaz de orientar todas as ações e fases da operação global de ensinar língua [ALMEIDA FILHO, 1996].” (In Rocha et al, 1998, p.2).
} 
XAVIER \& URIO - O professor de inglês e o livro didático: que relação é essa?

serem propostas, nas habilidades lingüísticas a serem priorizadas e nos objetivos de aprendizagem, o que não significa, necessariamente, uma perda de autonomia ${ }^{2}$ ou senso crítico do professor.

Por outro lado, é o professor quem seleciona esse recurso, dependendo do contexto de ensino. Ao se engajar nessa tarefa, no entanto, inúmeras influências concorrem para a sua escolha, como (1) as estratégias de marketing utilizadas pelas editoras (Carmagnani, 1999), que disponibilizam catálogos e exemplares gratuitos para análise, além de promoverem visitas à escola para a demonstração do material; (2) o preço do livro; (3) seus aspectos visuais (i.e. ilustração, layout, qualidade do papel), tornando-se objeto de desejo; (4) sua disponibilidade no mercado (Garinger, 2001) e (5) sua abordagem de ensinar e aprender.

No processo de escolha, aspectos técnicos, financeiros e práticos podem sobrepor-se a aspectos pedagógicos (Carmagnani, 1999; Garinger, 2001). Entretanto, se considerarmos que a função primordial do livro didático, em contextos do ensino básico, é desenvolver conhecimentos, competências e habilidades necessárias para a inserção crítica e participativa dos alunos na sociedade e no mundo, aspectos pedagógicos devem ser considerados prioritários, fazendo jus ao seu papel e relevância no ambiente escolar. Deste modo, cabe ao professor não se deixar influenciar pelas tendências do mercado editorial, tomando suas próprias decisões com critérios e reflexão crítica.

Para subsidiar o professor na seleção de um livro ou coleção didática de língua estrangeira, alguns estudiosos propõem critérios de avaliação apresentados em forma de uma lista de aspectos gerais a serem considerados (Vide Ur,1991), de perguntas avaliadoras dispostas em uma lista de verificação (evaluation checklists) (Garinger, 2001, 2002; Richards, s/d) ou, ainda, de um guia de avaliação (Bohn, 1988).

Em seu livro A Course in Language Teaching, Ur (1991) lista alguns critérios que podem nortear a avaliação de um livro didático, cabendo ao professor considerar aqueles mais importantes ou relevantes para essa tarefa. Tais critérios envolvem: a explicitação e operacionalização dos objetivos de aprendizagem; a adequação da abordagem à clientela; a qualidade do layout (claro e atrativo) e da impressão (legível); materiais visuais adequados e disponíveis; tópicos e tarefas interessantes; variedade de tópicos e tarefas para atender diferentes níveis de aprendizes, estilos de aprendizagem e interesse; instruções claras; abrangência do conteúdo de ensino; conteúdo claramente organizado e seqüenciado (por dificuldade); revisões periódicas e seções com exercícios/ atividades; linguagem autêntica; explicação e prática de pronúncia; explicação e prática de vocabulário; apresentação e prática de gramática; prática da fluência nas quatro habilidades lingüísticas (ouvir, falar, ler e escrever); desenvolvimento de estratégias de aprendizagem para tornar os aprendizes mais autônomos; orientação adequada ao professor, sem sobrecarregá-lo no planejamento das atividades; fitas cassetes e livro facilmente adquirido.

\footnotetext{
2 A autonomia do professor pode estar relacionada às suas atitudes, decisões e postura frente aos valores ideológicos dominantes que limitam as possibilidades da ação docente (BORGES, 2002).
} 
As listas de verificação, por sua vez, permitem pormenorizar aspectos lingüísticos ou práticos, através de perguntas previamente elaboradas para o professor, como mostra o excerto a seguir.

\section{Considerações relacionadas à língua}

Habilidades (lingüística e cognitiva)

- O livro integra as habilidades lingüísticas de maneira satisfatória? Há um equilíbrio entre elas?

- Ele focaliza na(s) habilidade(s) que propõe desenvolver?

- O livro contempla habilidades cognitivas mais elevadas? Desenvolve uma variedade de habilidades cognitivas?

\section{Considerações práticas}

\section{Layout/ Características Físicas}

- O livro didático é interessante? Atrativo? Há uma mistura apropriada de gráficos e texto?

- Ele é claro? Bem organizado? Apresenta uso efetivo de títulos?

(Garinger, 2001, p.5)

No guia de avaliação proposto por Bohn (1988), oito grandes categorias são apresentadas: geral, aspectos técnicos, compreensão oral, leitura, expressão oral, expressão escrita, vocabulário e gramática. Cada categoria é subdividida em itens, que podem ser expandidos conforme os objetivos de ensino do professor e as necessidades dos alunos. Formam, assim, o construto teórico para a avaliação. Cada item deve receber uma nota de 1 a 4 com base no nível de importância atribuído pelo professor (em uma coluna específica para isso, à esquerda) e com base no que o material oferece/ não oferece (em uma outra coluna destinada a isso, à direita), como ilustra o exemplo abaixo. 
XAVIER \& URIO - O professor de inglês e o livro didático: que relação é essa?

Categoria Leitura

\begin{tabular}{|c|c|c|}
\hline OBJETIVOS & ITENS A CONSIDERAR & MATERIAIS \\
\hline & $\begin{array}{l}\text { Os materiais oferecem: } \\
\text { - exercícios comunicativos } \\
\text { - exercícios sobre estratégias } \\
\text { - exercícios variados } \\
\text { - textos relacionados com o contexto } \\
\text { - cultural do aluno } \\
\text { - textos acessíveis aos alunos } \\
\text { - textos variados em forma e estilo } \\
\text { - textos suficientes } \\
\text { - textos atênticos } \\
\text { - textos interessantes } \\
\text { - textos com ideologias variadas } \\
\text { - } \\
\text { Os materiais sugerem leituras suplementares }\end{array}$ & \\
\hline
\end{tabular}

(Bohn, 1988, p.303)

As correlações entre os pesos expressos na coluna dos objetivos e na do material possibilitam ao professor-avaliador decidir-se sobre a adequação/escolha ou não do material avaliado.

Ainda, a título de referência no trabalho avaliativo e seletivo de materiais, Cunningsworth (1995 apud Richards, s/d, p. 05) propõe quatro diretrizes para a avaliação de livros didáticos:

1. Devem corresponder às necessidades dos alunos. Devem ainda atender aos objetivos gerais e específicos do curso;

2. Devem retratar os usos da língua. Devem também ajudar os alunos a usar a língua para propósitos pessoais;

3. Devem facilitar o processo de aprendizagem, sem impor um "método" rígido;

4. Devem funcionar como um apoio para a aprendizagem. Como professores, os livros didáticos fazem a mediação entre a língua-alvo e o aprendiz.

Estas diretrizes não visam especificar aspectos a serem avaliados em um livro didático, mas traçar critérios gerais que possam embasar a perspectiva de avaliação a ser conduzida pelo professor. 
É importante ressaltar que o livro didático, muitas vezes, não atende a todos os critérios de avaliação estabelecidos pelo professor. Isso significa dizer que não existe um "livro perfeito" às condições de ensino de cada professor, por melhor que ele se apresente. É o que concluem Assis \& Assis (2003, p. 318):

Não importa quão bom seja o livro didático em questão, ele geralmente não abarca em sua totalidade os interesses e necessidades de uma turma. Há que se adaptar, ampliar, variar as atividades e apresentações de conteúdo para atender aos propósitos daquele grupo específico de alunos.

Da mesma forma, “os materiais não devem ser considerados como uma panacéia que vai substituir os maus ou mal treinados professores ou que os professores bons não precisam de materiais." (Bohn, 1988, p.293). É o professor que deve exercer sua autonomia e senso crítico sobre o livro didático, de modo a gerenciar o seu ensino conforme seu senso de plausibilidade ${ }^{3}$.

\section{METODOLOGIA}

A princípio, pretendia-se fazer um levantamento de dados com quarenta professores de inglês, dos quais vinte seriam de escolas de ensino básico (escola pública e particular) e outros vinte de escolas de idiomas da cidade de Caçador - SC. Entretanto, isto não foi possível devido ao número reduzido de escolas de idiomas e, conseqüentemente, de professores de inglês atuando nesse contexto. Além disso, algumas escolas demonstraram receio em ter o seu material instrucional avaliado.

Por outro lado, os professores das escolas públicas demonstraram maior receptividade em contribuir com este estudo. Alguns, no entanto, não puderam retornar seus questionários devido ao acúmulo de trabalho extraclasse (ex.: correção de provas, entrega de notas) e ao seu envolvimento na greve, que havia se deflagrado no período da coleta de dados. Esses foram os principais entraves que dificultaram o cumprimento do número inicial de informantes para este estudo.

Foi possível, finalmente, obter a colaboração de somente trinta professores de inglês, dos quais dezoito atuam no ensino fundamental e médio (12 em escola pública e 6 em escola particular) e outros doze em escolas de idiomas. Todos responderam a um questionário com vinte e duas questões (Vide Anexo I), permitindo conhecer os profissionais que estão atuando nesses contextos, as informações que utilizam e descartam no livro didático, suas concepções sobre esse recurso (vantagens, desvantagens, seu papel e potencial) e seus critérios de seleção e avaliação.

Dos professores pesquisados, dezoito adotam livro didático/apostila determinado(a) pela escola (contexto público e privado de ensino básico e escolas de idiomas), quatro

3 Senso de plausibilidade é o entendimento subjetivo dos professores sobre o seu próprio ensino (Prabhu, 1990, p. 172). Segundo Prabhu (1990), os professores precisam operar com algum conceito pessoal sobre a relação causal entre o seu ensino e os ganhos de aprendizagem obtidos. 
XAVIER \& URIO - O professor de inglês e o livro didático: que relação é essa?

escolhem livremente o livro didático que querem adotar (contexto público e privado de ensino básico), quatro fabricam sua própria apostila (contexto público de ensino básico) e quatro não adotam qualquer livro ou apostila (contexto público e privado de ensino básico).

Durante a coleta de dados, muitos professores criticaram algumas perguntas do questionário, argumentando que eram semelhantes (i.e., Perguntas 13 e 17; 14 e 15). Diante disso, algumas questões ficaram sem resposta e outras traziam ressalvas como: "já respondi na questão anterior" ou "já respondi na questão X". Esta crítica foi pertinente e sinaliza a limitação metodológica deste trabalho, já que o questionário deveria ter sido testado antes de ser aplicado entre os professores. Por outro lado, a presença de perguntas convergentes fez com que os dados fossem replicados, reforçando, complementando ou, em alguns casos, amadurecendo certas idéias e concepções anteriormente colocadas.

Os dados receberam tratamento estatístico e as respostas abertas foram categorizadas, utilizando códigos descritivos para facilitar a análise e interpretação. Inicialmente, a análise foi realizada numa perspectiva geral sobre os dados apresentados. Num segundo momento, pontos de convergência e divergência foram traçados entre os professores dos dois contextos pesquisados (i.e. escola básica e de idiomas).

As seguintes siglas serão usadas neste estudo para distinguir os informantes ao longo da análise dos dados: PEE - Professoras de Escolas Estaduais; PEP - Professoras de Escolas Particulares e PEI - Professoras de Escolas de Idiomas.

\section{AS PARTICIPANTES DA PESQUISA}

Dos trinta informantes, 93,3\% são do sexo feminino, o que reforça a idéia de que a profissão do magistério continua sendo exercida, na sua grande maioria, por mulheres. Diante dessa estatística, utilizaremos o termo "professoras" doravante para designar as professoras e os professores pesquisados.

A faixa etária das professoras oscila entre 17 a 59 anos. As que atuam nas escolas básicas do ensino fundamental e médio (setor público e privado) estão em idade que varia entre 27 e 43 anos. As professoras abaixo dessa média (i.e. 17 a 23) e as que estão acima (i.e. 44 a 59) atuam nas escolas de idiomas.

A maioria das professoras tem tempo de serviço acima de cinco anos. As que têm abaixo desse tempo podem ser encontradas nas escolas de idiomas e nas escolas públicas.

Aproximadamente $80 \%$ das professoras trabalham exclusivamente em um único tipo de escola (i.e. na escola pública ou particular do ensino básico ou em escola de idiomas). As restantes completam sua carga horária, atuando em diferentes tipos de escola ou níveis de escolarização (ex.: escola pública e particular do ensino básico; escola particular de ensino básico e escola de idiomas; escola particular de ensino básico e universidade).

Observou-se que, na escola de idiomas, existe um grande número de professoras de inglês sem formação universitária (50\%), bem como profissionais com curso universitário, mas sem habilitação devida para atuar como professor de inglês. São profissionais formados em Psicologia, Engenharia Química, Processamento de Dados, Nutrição e Saúde Mental. 
Por outro lado, todas as professoras pesquisadas que atuam nas escolas do ensino básico (público e privado) são formadas no curso de licenciatura em Letras - Português e Inglês. Vale ressaltar que aproximadamente $44,4 \%$ dessas professoras possuem algum curso de pós-graduação, seja na área de línguas (ex.: Especialização em Língua Portuguesa e Comunicação; Especialização em Língua Inglesa; Especialização no Ensino de Línguas), seja na área de educação (ex.: Especialização em Psicopedagogia; Mestrado em Educação). Os dados sinalizam que muitas professoras de inglês que atuam no ensino básico não se acomodam na profissão, procurando atualizar-se por meio de cursos de especialização.

\section{O LIVRO DIDÁTICO NO FAZER DAS PROFESSORAS}

Com base nos depoimentos apresentados, os quatro recursos didático-pedagógicos indispensáveis para qualquer professor de inglês são: o aparelho de som, dicionários de inglês, livro didático e quadro de giz. Considerando cada um dos contextos escolares, verificou-se que este resultado permanece o mesmo.

O aparelho de som é o recurso mais aclamado entre as professoras pesquisadas, o que pode sugerir o tipo de atividades que elas priorizam em sala de aula (i.e. voltadas para a compreensão e expressão oral). Além desse recurso, o livro didático (LD doravante) aparece na lista, sugerindo sua influência, em particular, na prática pedagógica das PEPs e, principalmente, na das PEIs, que também ressaltaram a importância do manual de ensino.

Ao serem questionadas sobre o que o LD representa para a sua prática pedagógica, a maioria das professoras afirmou ser ele "um bom aliado", "um recurso indispensável", "necessário" e "essencial" para o bom desenvolvimento das aulas, o que demonstra uma certa confiança por parte das professoras nesse recurso.

Em geral, o LD é visto pela maioria das informantes como um "subsídio/apoio" e um "complemento" para o ensino do professor e para a aprendizagem dos alunos. É o que ilustra o Quadro 1, a seguir, com as vozes das professoras. 
XAVIER \& URIO - O professor de inglês e o livro didático: que relação é essa?

Quadro 1 - As concepções das professoras sobre o LD

\begin{tabular}{|c|l|}
\hline Concepções de LD & \multicolumn{1}{|c|}{ Vozes das professoras } \\
\hline \multirow{3}{*}{ subsídio/ apoio } & $\begin{array}{l}\text { PEE 04 - ..um instrumento que auxilia, às } \\
\text { vezes, na realização de alguns exercícios e na } \\
\text { leitura de alguns textos, porque em algumas } \\
\text { escolas a reprodução de materiais é precária. } \\
\text { PEE 05 - ..um suporte para melhor auxiliar-me } \\
\text { a orientar meu aluno. } \\
\text { PEP 02 - ..um instrumento de pesquisa, do qual } \\
\text { utilizo o que há de bom e necessário. }\end{array}$ \\
\hline complemento & $\begin{array}{l}\text { PEP } 05-\ldots \text { um complemento às verdadeiras } \\
\text { aulas. } \\
\text { PEI 06 }-\ldots \text { um complemento para que o aluno } \\
\text { possa fazer os exercícios, tendo contato com a } \\
\text { parte escrita da língua, podendo assim, fixar } \\
\text { melhor o que foi aprendido oralmente. } \\
\text { PEI 11 - um excelente complemento/auxiliar } \\
\text { para que o professor comunique os } \\
\text { conhecimentos ao aluno. }\end{array}$ \\
\hline
\end{tabular}

A maioria das professoras mostrou ter consciência de que o LD é importante, mas não onipotente. Daí o uso de palavras como "complemento", "suporte", "subsídio"e "apoio". Não é, portanto, um recurso completo em si mesmo, dado as suas limitações quanto à quantidade e qualidade das informações apresentadas.

PEE 02 -... Um dos recursos utilizados; não considero os livros didáticos completos.

PEP 04 -... Um recurso de apoio, mas que ainda está distante da realidade do aluno.

PEI 09 -... Essencial. É preciso ter um livro para seguir e se basear. Não é necessário segui-lo à risca, mas importante para se basear.

Nas escolas de idiomas, por outro lado, o LD é visto como guia norteador, um instrumento indispensável para o processo de ensino e aprendizagem. Para PEI 07, em particular, "sem um livro didático, o professor poderá ficar perdido, prejudicando os alunos."

Em geral, o LD assume as seguintes funções para as professoras pesquisadas: (1) orientar as ações pedagógicas, (2) auxiliar e facilitar o trabalho do professor, (3) complementar as aulas e a aprendizagem dos alunos e (4) estabelecer o conteúdo de ensinoaprendizagem e a sua sequiência. 
Quanto à função social e política do $\mathrm{LD}$, algumas professoras demonstraram pouca ou nenhuma clareza sobre o papel desse instrumento na formação de cidadãos participativos e críticos na sociedade. Suas respostas foram vagas, tangenciais e pouco esclarecedoras. Outras professoras, no entanto, afirmaram que os LDs de inglês assumem este papel quando abordam aspectos culturais da língua estrangeira ou de outras línguas e assuntos atuais através dos textos apresentados.

Por outro lado, houve professoras que afirmaram que não cabe ao LD, exclusivamente, desenvolver o senso crítico dos alunos, mas ao professor, através de sua metodologia.

PEE 09 - Não é só o livro que torna os cidadãos críticos e participativos, seus assuntos podem contribuir, mas principalmente a metodologia que o professor utiliza na sala, em suas atividades.

PEP 06 - Depende do posicionamento do professor, da forma com a qual ele irá conduzir sua aula. Pode-se ter acesso ao melhor material, se o professor não souber conduzilo, a aula não será boa, não se desenvolverá o senso crítico do aluno.

PEI 11 - Depende muito da abordagem que o professor faz.

Algumas professoras ainda redimiram o LD deste papel (ex.: PEI 12 - A formação de indivíduos mais participativos e críticos na sociedade independe do livro didático de inglês.).

A função do LD de língua estrangeira certamente transcende o ensino e a aprendizagem da língua e de sua cultura. É ele, também, o responsável por abordar assuntos que possam provocar a discussão e reflexão crítica sobre a sociedade em que vivemos (ou a sociedade que queremos), a partir dos textos e das atividades propostas. A distância temática e os vícios metodológicos que, muitas vezes, os LDs cultivam esvaziam sua função social e política na escola, mascarando a realidade e banalizando a capacidade de pensar dos alunos.

Aproximadamente 51,8\% das professoras pesquisadas concordam que a maioria dos LDs de inglês atende, parcialmente, às suas necessidades e às dos alunos. Elas apontam limitações quanto (1) à abrangência do LD (ex.: PEE 09 - Em algumas atividades ele atende, sendo outras necessárias o professor complementar; PEP 01 - Há livros que não atendem às necessidades, devendo ser constantemente complementados); (2) à abordagem de ensino-aprendizagem subjacente (ex.: PEE 04 - Alguns livros tratam a língua como um círculo fechado, não a tratam como um objeto vivo e que vive com as pessoas e sofre as alterações, assim sendo, o aluno passa anos vendo e repetindo o mesmo assunto, o que bitola e prejudica o seu conhecimento; PEI 09 - Em geral, os livros didáticos de inglês dão muita ênfase às regras gramaticais, e, muitas vezes, com explicações superficiais) e (3) ao conteúdo e metodologia (ex.: PEI 08 - Alguns atendem às nossas realidades e às necessidades dos alunos, mas a maioria tem conteúdos que deixam a desejar e explicações fracas e superficiais; PEP 04 - Alguns livros estão muito distantes da realidade do aluno, do seu "mundo").

Estes dados reforçam a concepção de que o LD, para a maioria das professoras, não é suficiente para atender às necessidades e aos interesses dos alunos. Precisa, portanto, de complementação e adequação. 
XAVIER \& URIO - O professor de inglês e o livro didático: que relação é essa?

É importante salientar que "atender aos interesses dos alunos" significa, para algumas professoras, considerar recursos tecnológicos, a realidade dos alunos e a metodologia do professor. Por meio desses elementos, acredita-se promover a motivação e assegurar relevância no processo de aprendizagem.

Nota-se ainda que o tempo e a praticidade são, para as professoras, fatores importantes no contexto de sala de aula; e que o LD pode, conseqüentemente, maximizar esse tempo e as suas ações, bem como a dos alunos, agilizando o processo de ensino e aprendizagem. Pode-se dizer, assim, que este recurso cria uma zona de conforto para os seus usuários. Por essa razão, ele é visto como um facilitador do trabalho pedagógico e da aprendizagem.

Para algumas professoras das escolas de idiomas, além de trazer "informações", o LD ainda proporciona uma certa segurança ao professor e aos alunos (ex.: PEI 07 Segurança e informação; PEI 11 - O método $X$ dá muita segurança ao professor e ao aluno). Esta sensação também é retratada no trabalho de Menegazzo \& Xavier (2004), quando as autoras afirmam que:

\begin{abstract}
Algumas escolas de línguas utilizam ainda a noção de método para padronizar a prática pedagógica dos professores. Daí os cursos de treinamento que estabelecem o que vai ser ensinado e geralmente como, muitas vezes com base no livro didático adotado. Se, por um lado, é possível afirmar que o método prescreve receitas pedagógicas, inibindo a autonomia didática do professor e, por conseguinte, seu autoconhecimento como profissional, por outro, ele atrai professores que acreditam nessas receitas como solução de problemas que ocorrem em sala de aula. O método, portanto, parece dar uma sensação de conforto e segurança para certos professores. (p.116)
\end{abstract}

Se adotar um LD parece ser um bom negócio para as professoras, por outro lado pode tornar-se uma armadilha, ou seja, pode trazer um sentimento de obrigação de cumprir o conteúdo e aplicar todas as atividades. É o que algumas professoras salientam, a seguir, quando questionadas sobre as desvantagens de se usar ou adotar um LD:

PEE 09 - Seguir o livro didático à risca sem utilizar outros recursos e metodologias. PEP 06 - [...] Deve-se aprender [sic] ao livro devido à cobrança dos pais.

PEI 12 - Quando o professor restringe a sua criatividade, pesquisa e preparação das aulas apenas ao livro didático.

Quando questionadas sobre a sua reação ao se depararem com textos ou exercícios com os quais não se simpatizam em um LD, as professoras afirmaram assumir posturas diferentes. Algumas disseram substituí-los por outros textos/exercícios que estejam "relacionados com a realidade dos alunos", que sejam "atrativos" e alinhados com os "objetivos do conteúdo".

Outras professoras preferem adaptar os exercícios, sugerindo "técnicas" (PEI 08), "forma mais dinâmica" (PEI 04), "forma nova" (PEI 01) ou "forma diferente" (PEI 05) para torná-los mais atraentes. Nota-se que "adaptar" significa, para essas professoras, adotar procedimentos ou estratégias de ensino que possam tornar a atividade mais simpática. Neste sentido, o exercício não é descartado, mas analisado para mudanças metodológicas (i.e. na maneira como conduzi-lo). 
Algumas justificativas sobre não descartar atividades antipáticas residem em pressões institucionais:

PEI 07 - No caso de uma franquia, como a XXXX, devemos seguir todos os passos sem modificações, já que é um método cientificamente elaborado.

PEI 09 - Como trabalho para uma franquia, eu preciso seguir tudo o que está no livro didático, apesar de algumas vezes não simpatizar com algumas atividades. No entanto, tento fazer com que se torne mais atraente, principalmente para os alunos mostrando os pontos positivos em tal atividade.

Outras justificativas baseiam-se em posicionamentos próprios ou pressões externas ao contexto escolar:

PEE 08 - O livro didático obriga-nos a estar diante dele o tempo todo, já que foi adquirido, temos que aproveitá-lo.

PEP 05 - Podemos nos sentir obrigados a segui-lo na íntegra (pressões).

PEP 06 - Procuro selecionar os mais importantes, porém não deixo de resolver os menos relevantes, devido à cobrança dos pais, porém só não lhes será dada ênfase.

Foi possível observar que algumas professoras demonstram consciência quanto ao risco do seu apego e o dos alunos ao LD. Nas palavras de PEP 05, o ponto negativo do LD é o perigo de "ser dominado" por ele. PEE 03 salienta o cuidado em adotá-lo "como cartilha” e PEE 11 afirma que, “às vezes, o livro didático 'vicia' os alunos”, que só querem trabalhar com esse recurso.

\section{O PAPEL DO MANUAL DE ENSINO}

Os dados mostraram que o manual de ensino (ME doravante) é um recurso também presente na prática das professoras, as quais disseram utilizá-lo "algumas vezes" $(46.6 \%)$ ou "sempre" (43,3\%).

No contexto das escolas do ensino fundamental e médio (setor público e privado), as professoras disseram seguir, algumas vezes, as orientações do ME, o que não acontece no contexto das escolas de idiomas, onde a maioria das professoras $(83,3 \%)$ considera este recurso um aliado, utilizando-o sempre no trabalho pedagógico. A forte presença do $\mathrm{ME}$ entre as PEIs pode ser explicada pelo sistema franqueado de ensino que requer padronização metodológica, isto é, os professores devem assumir e utilizar a mesma metodologia de ensino frente ao material instrucional. O ME, portanto, serve de norteador para as ações pedagógicas, sinalizando a metodologia a ser seguida.

Dentre as informações que a maioria das professoras costuma seguir em um ME, estão as sugestões de atividades extras, as orientações metodológicas e as informações teórico-metodológicas. Esses resultados não se alteram se analisarmos as respostas da 
XAVIER \& URIO - O professor de inglês e o livro didático: que relação é essa?

maioria das professoras em cada contexto pesquisado. Orientações sobre como avaliar os alunos, o gabarito das atividades e a bibliografia complementar não são, conforme os dados, informações que as professoras geralmente procuram em um ME.

Para confirmar e complementar esses dados, as professoras foram solicitadas a dizer o tipo de informação necessária e desnecessária em um ME. Verificou-se que, novamente, as orientações/sugestões metodológicas e as atividades extras são informações necessárias, segundo as professoras. Elas ainda esperam que o ME possa trazer-lhes informações lingüísticas e culturais sobre os países de língua inglesa, sinalizando que o ME possa tornarse um documento informativo lingüístico-cultural, além de teórico-metodológico.

Esta expectativa sugere a carência do professor no conhecimento lingüístico e cultural mais aprofundado sobre a língua que ensina, o que amplia a função do ME como instrumento não apenas de ensino, mas também de aprendizagem do professor. Além disso, a consulta às sugestões metodológicas e às atividades extras fornecidas no ME demonstra a procura do professor pela diversificação metodológica, tendo como objetivo fomentar a motivação em sala de aula.

Quanto às informações desnecessárias, algumas professoras citam as orientações sobre avaliação, a forma de correção dos exercícios e o gabarito. Não existe, portanto, um interesse sobre essas questões.

\section{OS CRITÉRIOS DE SELEÇÃO}

Dentre as professoras que disseram seguir o $\mathrm{LD}$ / a apostila determinado(a) pela escola (18), duas participaram da seleção desse material em consenso com os demais professores de área. Foi, portanto, uma decisão conjunta e não imposta pela escola.

As professoras que não adotam LD (4) e aquelas que elaboram sua própria apostila (4) costumam utilizar exercícios e textos de vários livros didáticos ou da Internet, além de criarem suas próprias atividades. O mesmo acontece com as professoras das escolas públicas e particulares pesquisadas que adotam LD/apostila. Elas afirmaram que não se limitam ao uso exclusivo do LD; tendem a diversificar seu ensino com atividades extras.

Quanto às professoras que têm a liberdade de escolher o LD (4), os dados mostraram que a seleção desse instrumento é feita com base no seu preço acessível e na boa organização e apresentação do conteúdo instrucional. O primeiro critério foi citado pelas professoras da escola pública, o que demonstra sua preocupação com o poder aquisitivo dos alunos. A relação preço versus vantagens do produto também foi considerada, como sugere PEE 12, ao ser questionada sobre os motivos que a levaram a escolher o LD X: "O preço estava acessível e por ser volume único. O livro será utilizado nas três séries do Ensino Médio.".

A partir desses critérios (financeiro, estético e prático), percebe-se uma falta de prioridade com questões pedagógicas, como o conteúdo e a metodologia propriamente ditos. Estas questões, as quais determinam a abordagem de ensinar das professoras, podem integrar a primeira fase de seleção do LD. Ou seja, somente os livros que se aproximam da abordagem do professor fazem parte inicialmente da triagem, ficando a escolha final a 
critério de aspectos financeiros, estéticos e práticos. Nesta perspectiva, os LDs que se distanciam da abordagem do professor têm poucas chances de serem escolhidos, exceto se eles apresentarem um certo potencial para a subversão metodológica. É o caso de livros fabricados numa perspectiva funcional (i.e. apresentação de funções comunicativas em contextos de uso da língua-alvo) que, metodologicamente, podem ser trabalhados numa perspectiva gramaticalista, fragmentando as funções para o trabalho de conscientização gramatical de suas partes. Na verdade, a subversão metodológica pode acontecer em qualquer tipo de abordagem, dependendo das concepções de linguagem, ensino e aprendizagem que o professor carrega consigo.

As professoras que adotam LD/ apostila previamente determinado(a) pela escola também foram questionadas sobre as possíveis razões de a escola ter selecionado o LD/a apostila que usavam. O que teria ele (ela) de tão especial?

A grande maioria, em particular as professoras das escolas de idiomas, mostrou desconhecer as razões. Suas respostas não apresentaram qualquer tipo de critério, sendo expressas com noções vagas (ex.: PEI 02 - Método da franquia; PEI 04 - Porque é o livro que eles têm para o ensino; PEI 06 - O livro é próprio do curso. Ele é elaborado pelo XX; PEI 07 - Usamos o material didático $X$, por ser o que há de melhor e mais eficiente método para se aprender outro idioma; PEI 08 - Pela qualidade do material). Esse desconhecimento pode ser explicado pelo próprio sistema de franquia que não permite a participação dos professores na seleção desse material.

Para algumas professoras do ensino básico, os critérios de seleção do LD/ apostila adotado(a) pela escola estão relacionados aos conteúdos específicos para cada série, à forma como esses conteúdos são apresentados e aos objetivos de aprendizagem. A forte concepção de que cada série deve apresentar um conteúdo informacional próprio, em particular no ensino de inglês, sustenta os programas de curso voltados para o conhecimento de língua que os alunos deveriam aprender. Neste caso, quem estabelece o que vai ser aprendido é o LD/ a apostila. São os chamados programas voltados para o produto (productoriented syllabus) em oposição aos programas de processo (process-oriented syllabus) (Nunan, 1988), os quais priorizam experiências de aprendizagem sem a determinação prévia do conteúdo a ser aprendido. Cada aluno aprende ou apreende os conhecimentos de língua, conforme o seu foco de atenção, interesse, motivação, sendo responsável pela construção de sua própria interlíngua.

Na perspectiva de produto, predominante nos tipos de contextos pesquisados, criamse relações lingüísticas de dependência (ex.: $\mathrm{O}$ verbo to be deve ser ensinado antes do simple present) e é nesta direção que muitos LDs/apostilas de inglês se encaminham, seja de forma explícita ou camuflada.

Ainda com base nos dados, foi possível conhecer os critérios mais importantes que as professoras, em geral, consideram na escolha de um LD de inglês. Os critérios estão listados a seguir:

(1) os exercícios/atividades devem ser diversificados(as) e complementar ou reforçar o conteúdo estudado. São preocupações, portanto, quanto à necessidade de o $\mathrm{LD}$, através 
XAVIER \& URIO - O professor de inglês e o livro didático: que relação é essa?

de seus exercícios, assegurar a motivação dos alunos, fomentar seu raciocínio e fixar o conteúdo;

(2) os conteúdos, assim como as atividades propostas, devem ser bem elaborados, dosados e graduados, o que sugere uma preocupação com a sequiência "lógica" dos conteúdos, sinalizando a visão linear de progresso ou crescimento no aprendizado;

(3) os textos devem ser atuais, interessantes, variados e voltados para a realidade dos alunos. Este critério está relacionado à busca pela relevância e significado social dos assuntos tratados em aula, como forma de promover maior motivação e engajamento dos alunos;

(4) a gramática deve ser apresentada de maneira clara e eficiente. Por eficiência, as professoras referem-se às "boas explicações" ou aos "resumos gramaticais" que podem tratar o assunto de forma objetiva e atraente. Esta expectativa nos remete à criatividade do LD em tornar assuntos considerados desinteressantes, para os alunos, em assuntos prazerosos, um milagre que poucos conseguem.

É possível concluir que a qualidade dos textos e dos exercícios, bem como a forma de apresentação do conteúdo instrucional (gramática e outros), são aspectos importantes no processo de seleção de um LD de inglês, conforme os dados apontam. As preocupações das professoras residem basicamente nos exercícios que diversificam, complementam e reforçam o conteúdo, na sua organização, dosagem e graduação, na motivação através dos textos e na apresentação da gramática.

Se considerarmos que o professor já traz consigo definido o conteúdo e os objetivos de ensino para a seleção do LD, de acordo com a sua visão de linguagem e de ensino de língua, é possível sugerir que não é o LD que determina o que vai ser ensinado, mas o professor, ao fazer um levantamento inicial dos materiais que se aproximam de sua abordagem. A função desse recurso resume-se, portanto, a especificar o conteúdo a ser ensinado (ex.: Que itens gramaticais? Que itens funcionais?) e estabelecer a rota metodológica a ser seguida.

\section{A AVALIAÇÃo DO LIVRO DIDÁTICO}

$\mathrm{Na}$ opinião das professoras, um LD de inglês bom ou ótimo deve primar pelo seu layout, pelo seu conteúdo e apresentação e pelos seus objetivos de ensino-aprendizagem. Deve ainda atender aos princípios comunicativos de língua e trazer sugestões metodológicas para o professor. Estes são os elementos sugeridos nas falas das professoras ao avaliarem a qualidade de um LD. O Quadro 2, a seguir, traz algumas opiniões, especificando os elementos que consideram importantes no processo de avaliação de um LD de inglês. 
Trab.Ling.Aplic., Campinas, 45(1) - Jan./Jun. 2006

Quadro 2 - Elementos considerados na avaliação de um livro didático de inglês.

\begin{tabular}{|c|c|c|}
\hline Elementos Gerais & Elementos Específicos & Algumas Vozes \\
\hline Layout & Ilustrações & $\begin{array}{l}\text { PEI } 02-[\ldots] \text { ser ilustrado }[\ldots] . \\
\text { PEI } 06 \text { - textos com ilustrações. }\end{array}$ \\
\hline \multirow{4}{*}{ Conteúdo instrucional } & Adequação à clientela & $\begin{array}{l}\text { PEE } 09 \text { - Deve estar voltado para a faixa etária [...]. } \\
\text { PEI } 05 \text { - Deve ter o conteúdo relacionado com a } \\
\text { realidade dos alunos. }\end{array}$ \\
\hline & Organização e sequiência & $\begin{array}{l}\text { PEE } 06 \text { - Conteúdos bem elaborados [...]. } \\
\text { PEI } 12 \text { - O conteúdo deve ser apresentado de uma } \\
\text { forma coerente e em sequiência. }\end{array}$ \\
\hline & Qualidade dos textos & $\begin{array}{l}\text { PEE } 02-[\ldots] \text { textos interessantes, informativos, } \\
\text { educativos, que despertem os alunos para as questões } \\
\text { sociais e ecológicas. } \\
\text { PEP } 05 \text { - Textos diversos (originais, mais adaptados). }\end{array}$ \\
\hline & Gramática & $\begin{array}{l}\text { PEP } 05 \text { - Não existir regras gramaticais em excesso. } \\
\text { PEI } 10 \text { - Deve ter uma boa sequiência na apresentação } \\
\text { dos pontos gramaticais e fazer isso com clareza. }\end{array}$ \\
\hline \multirow{2}{*}{ Metodologia } & Tipos de exercício & $\begin{array}{l}\text { PEE } 02-[\ldots] \text { exercícios criativos que despertem o } \\
\text { interesse do aluno. } \\
\text { PEP } 06 \text { - Deve possuir exercícios inteligentes, que visem } \\
\text { à construção do conhecimento do aluno e não meras } \\
\text { repetições. }\end{array}$ \\
\hline & $\begin{array}{l}\text { Apresentação dos } \\
\text { exercícios }\end{array}$ & $\begin{array}{l}\text { PEE } 08-[\ldots] \text { ele deve apresentar exercícios com muita } \\
\text { clareza, muitos deles não facilitam a interpretação dos } \\
\text { mesmos. } \\
\text { PEI } 05 \text { - forma de abordar os conteúdos, exercícios } \\
\text { [...]. }\end{array}$ \\
\hline $\begin{array}{l}\text { Objetivos de ensino e } \\
\text { aprendizagem }\end{array}$ & $\begin{array}{l}\text { Habilidades e } \\
\text { competências }\end{array}$ & $\begin{array}{l}\text { PEE } 11-[\ldots] \text { produção de textos para que o aluno } \\
\text { aprenda e aprecie o que está fazendo. } \\
\text { PEP } 02 \text { - Deve desenvolver as habilidades: Listening, } \\
\text { Spelling, Speaking, Understanding. }\end{array}$ \\
\hline \multirow[b]{2}{*}{$\begin{array}{l}\text { Aspectos teórico- } \\
\text { metodológicos }\end{array}$} & $\begin{array}{l}\text { Sugestões } \\
\text { metodológicas }\end{array}$ & $\begin{array}{l}\text { PEE } 06 \text { - Deve apresentar sugestões técnicas para } \\
\text { aprendizagem. } \\
\text { PEI } 07 \text { - A metodologia a ser seguida. }\end{array}$ \\
\hline & $\begin{array}{l}\text { Princípios comunicativos } \\
\text { da linguagem }\end{array}$ & $\begin{array}{l}\text { PEE } 04 \text { - Ter uma abordagem comunicativa. [...], } \\
\text { "listening", variantes lingüísticas, onde o aluno é o centro } \\
\text { da aluna, e não o professor. A língua precisa se } \\
\text { entendida e não decorada. } \\
\text { PEI } 11 \text { - Também deve ter um embasamento teórico } \\
\text { bem fundamentado para proporcionar segurança ao } \\
\text { aluno na hora em que ele precisar usar seus } \\
\text { conhecimentos em uma situação prática. }\end{array}$ \\
\hline
\end{tabular}


XAVIER \& URIO - O professor de inglês e o livro didático: que relação é essa?

Dentre os elementos mais citados estão os textos, o conteúdo instrucional (sua apresentação/ organização), os tipos de exercício e a apresentação da gramática. Para as professoras, um bom LD é aquele que traz textos "atuais", "interessantes", "informativos", "educativos", "atraentes" e "voltados para a realidade dos alunos"; conteúdo de ensino bem seqüenciado, dosado, adequado à faixa etária dos alunos e motivador; exercícios "variados", "criativos", "inteligentes", que "fixam e reforçam o conteúdo estudado". E, finalmente, a presença da gramática que deve ser bem dosada, "prática" e "objetiva".

A presença da gramática como um item a ser avaliado pode sugerir a abordagem de ensinar das professoras. Em outras palavras, a sistematização da língua estrangeira é vista como necessária em um bom LD e, para isso, sua apresentação deve ser clara e organizada. Promover consciência metalingüística nos alunos parece ser, portanto, um aspecto importante em um LD, segundo algumas professoras.

O nível de satisfação com a apresentação da gramática varia entre as professoras. Alguns aspectos negativos são apontados a seguir:

\section{Pontos negativos do LD:}

PEE 04 - Dão ênfase na gramática e não na comunicação.

PEE $12-[\ldots]$ Enfatiza a memorização de regras gramaticais.

PEI 08 - O excesso de dificuldade apresentado em certos pontos gramaticais, saindo do foco e dando mais atenção às exceções do que a regra em si.

É interessante salientar que a maioria das PEIs não vê pontos negativos nos livros didáticos, com exceção de algumas que destacam o excesso de informações desnecessárias, como a ênfase nas exceções gramaticais e nas regras.

Quanto aos textos, muitas professoras proclamam assuntos mais motivadores e atraentes, o que não significa, necessariamente, tornar a aprendizagem dos alunos mais significativa e relevante. Textos considerados interessantes podem ser utilizados em metodologias mais conservadoras. PEI 05, por exemplo, em sua fala a seguir, parece adotar uma abordagem tradicional de leitura, voltada para a tradução de textos. PEI 10, por sua vez, acredita que a aquisição de língua é promovida a partir do estudo de itens lingüísticos isolados, ensinados de maneira graduada. Nesta perspectiva, o texto assume a função de simplesmente contextualizar ou ilustrar certos itens lingüísticos.

PEE $05-[\ldots]$ Textos atuais, informativos, culturais que desenvolvam o imaginário do aluno, quando esse faz a leitura traduzindo o texto.

PEI 10 - [...] Deve ter uma boa seqüência na apresentação dos pontos gramaticais e fazer isso com clareza.

É sobre a temática dos textos que recai a maior insatisfação das professoras. A crítica está na falta de articulação dos temas com a realidade dos alunos, além de serem desatualizados e pouco atrativos. 
Para algumas professoras, o LD pode ainda desmotivar o aluno pela forma semelhante como os conteúdos são estruturados nas unidades de ensino. Neste caso, pode-se dizer que a metodologia do professor pode fazer a diferença através de estratégias de ensino diferenciadas.

Ao compararmos os critérios de avaliação com os de seleção/escolha do LD de inglês, é possível concluir que eles convergem para os mesmos pontos, uma vez que consideram a qualidade dos textos, a organização do conteúdo, os tipos de exercício e a apresentação da gramática como principais elementos a serem analisados no momento da avaliação e escolha do LD.

Visando conhecer a opinião das professoras quanto à qualidade dos livros didáticos produzidos no Brasil e no exterior, as mesmas foram solicitadas a se posicionar quanto à seguinte proposição: "Os livros didáticos de língua inglesa, publicados por editoras internacionais, são melhores que os livros didáticos de inglês de editoras nacionais". Aproximadamente 56\% das professoras discordaram da afirmação, $12 \%$ concordaram e $32 \%$ concordaram parcialmente, ressaltando algumas vantagens do LD importado sobre o nacional. Com base nas justificativas apresentadas, foi possível sistematizar alguns pontos positivos e negativos dos livros nacionais e importados. O Quadro 3 ilustra esses pontos.

Quadro 3 - Pontos positivos e negativos dos LDs nacionais e importados.

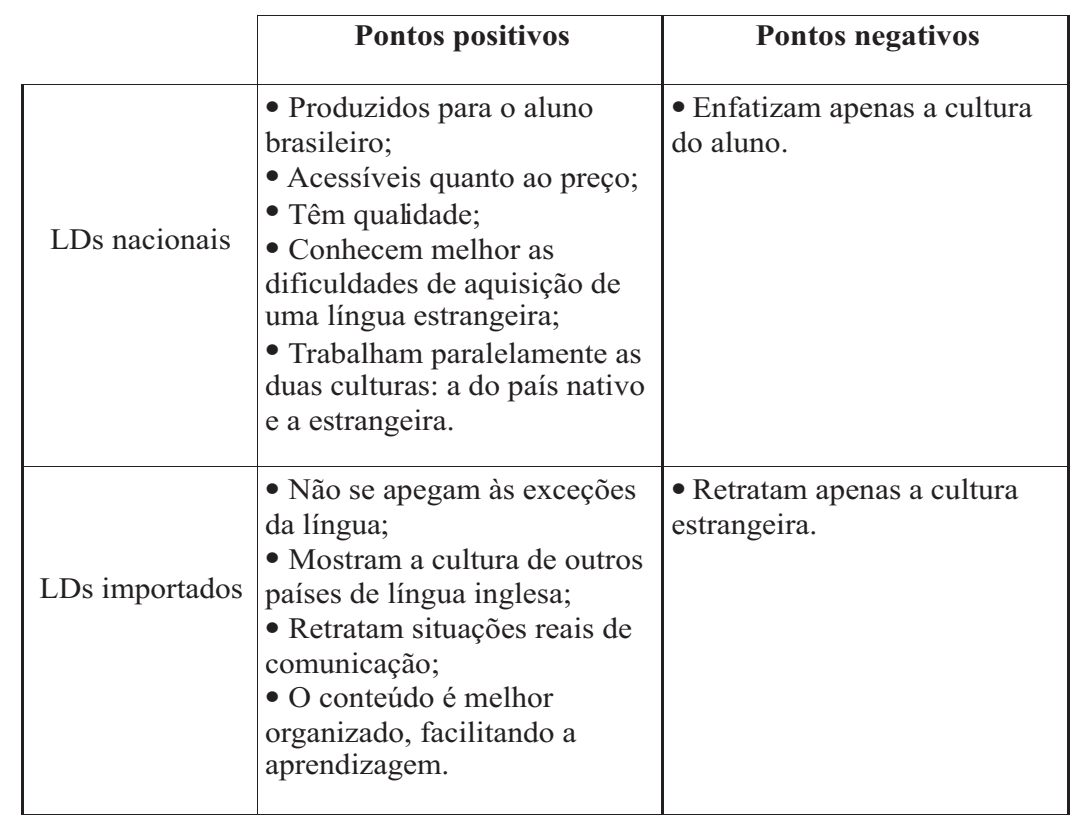


XAVIER \& URIO - O professor de inglês e o livro didático: que relação é essa?

Ao compararem o LD nacional ao importado, as professoras consideraram, principalmente, fatores como adequação do LD ao público-alvo e à sua cultura. Nesta comparação, o LD nacional mostrou ter vantagens sobre o importado por serem elaborados para o contexto educacional brasileiro. Conhecem, portanto, a nossa realidade. Por outro lado, acredita-se que o LD importado seja melhor que o nacional por apresentarem situações 'verdadeiras' de uso comunicativo da língua inglesa, sugerindo maior confiabilidade nas amostras lingüísticas oferecidas, como mesmo salienta PEI 08: "[Os livros importados] enfocam menos as exceções e usam vocabulário mais adequado e em situações reais." Conseqüentemente, fornecem um conteúdo instrucional mais apropriado à aprendizagem da língua estrangeira.

\section{CONCLUSÃO}

Com esta pesquisa, foi possível redimensionar o papel do LD e entender a sua relação com as professoras pesquisadas. Os dados mostraram que elas estabelecem uma relação de parceria com esse material. Embora facilite a condução do trabalho pedagógico, o LD não é auto-suficiente como salientam as professoras, as quais necessitam complementá-lo ou adaptá-lo às suas condições de ensino.

$\mathrm{Na}$ concepção das professoras, em geral, o LD representa um subsídio/apoio ou complemento para o seu ensino, servindo de roteiro ou mapa da trajetória pedagógica, que precisa ser complementado. Daí a visão flexibilizada do seu papel no processo de ensino e aprendizagem, exceto para as PEIs, que devem limitar o seu campo de ação e reflexão devido à padronização metodológica que devem seguir.

Para as PEIs, adaptar as atividades/os exercícios significa utilizar estratégias diferenciadas para o seu uso em sala de aula. São, portanto, ajustes metodológicos/ procedimentais feitos para a manutenção das atividades antipáticas. Neste caso, a relação entre essas professoras e o LD é mais rígida e essa rigidez pode congelar o seu senso de plausibilidade.

Observou-se também que o LD traz uma sensação de conforto para as professoras e alunos (em tempo e agilidade), mas cria um sentimento de compromisso com ele (cumprir conteúdo e atividades). Neste último caso, a relação torna-se um pouco conflituosa devido a questões institucionais (possíveis pressões da escola ou da família dos alunos).

Para as PEIs, que encontram-se inseridas num sistema de franquia, o LD e o ME caracterizam-se fortemente como um guia norteador capaz de padronizar as principais ações didático-pedagógicas a serem realizadas em conjunto com os demais docentes. Ao contrário, no contexto de escola básica, o ME parece pouco influenciar na prática das professoras pesquisadas, pois a maioria afirmou que "às vezes" utiliza esse recurso. Em geral, quando o ME é utilizado, as professoras buscam orientações/sugestões metodológicas, atividades extras e informações teórico-metodológicas, mas descartam as orientações de como avaliar os alunos, assim como o gabarito das atividades e a bibliografia complementar. 
Trab.Ling.Aplic., Campinas, 45(1) - Jan./Jun. 2006

Embora existam diferentes níveis de influência do LD na prática das professoras, dada a presença ou ausência de pressões no contexto de ensino e de fatores externos a ele, os dados mostram que o LD não parece satisfazer plenamente as suas expectativas. São insatisfações quanto à qualidade dos textos, geralmente distantes da realidade dos alunos, desatualizados e pouco atrativos; à apresentação/organização do conteúdo instrucional, que geralmente se estrutura da mesma forma ao longo das unidades; à abordagem de aprender subjacente, caracterizada por excessos ou pela pouca gramática apresentada (i.e. muitas exceções, muitas regras gramaticais, pouca ênfase na ortografia, explicações fracas e superficiais) e à falta de exercícios motivadores e mais envolventes cognitivamente (i.e. muitos exercícios mecânicos, ausência de atividades mais dinâmicas).

Estas questões estão relacionadas à criação de condições para a motivação dos alunos via LD. São estes, portanto, os principais elementos que as professoras geralmente analisam para a seleção e avaliação desse material, i.e. os textos, a organização do conteúdo, os tipos de exercício e a apresentação da gramática, responsáveis por promover a motivação dos alunos e facilitar o entendimento do conteúdo instrucional.

Os resultados aqui obtidos mostram sinais de flexibilidade na relação professor e LD (para as professoras do ensino básico), mas de rigidez para as professoras das escolas de idiomas, em cujos contextos os níveis de influência parecem ser maiores. No ensino básico, foi possível observar autonomia de algumas professoras no uso do LD, não se restringindo a ele no processo de ensino e aprendizagem.

Para finalizar, a importância deste material na vida do professor implica a necessidade de uma reflexão mais sistemática sobre os seus conteúdos e as maneiras de como trabalhálos, considerando objetivos de aprendizagem relevantes e significativos para o desenvolvimento do aluno-cidadão que participa e transforma a sociedade.

\section{$\overline{\text { REFERÊNCIAS BIBLIOGRÁFICAS }}$}

ASSIS, S. N. L. de \& ASSIS, R. E. de. (2003). Livro Didático: Yes, Sir! In: Anais do V Seminário de Línguas: A formação do professor de línguas estrangeiras. Goiânia: Editora Vieira.

BORGES, R. C. M. B. (2002). O professor reflexivo-crítico como mediador do processo de inter-relação da leitura-escritura. In: PIMENTA, S. G.; GHEDIN, E. (Orgs.). Professor reflexivo no Brasil: gênese e crítica de um conceito. São Paulo: Cortez.

BOHN, H.I. (1988). Avaliação de Materiais. In: BOHN, H.; VANDRESEN, P (Orgs.). Tópicos de Lingüística Aplicada: $O$ ensino de línguas estrangeiras. Florianópolis: EDUFSC.

CARMAGNANI, A.M.G. (1999). A concepção de professor e de aluno no livro didático e o ensino de redação em LM e LE. In: CORACINI, M. J. (Org.). Interpretação, Autoria e Legitimação do Livro Didático. Campinas: Editora Pontes.

DEMO, P. (1993). Desafios Modernos da Educação. Petrópolis: Vozes.

FARIA, A. L. G. de. (2000). Ideologia no Livro Didático. São Paulo: Atlas. 
XAVIER \& URIO - O professor de inglês e o livro didático: que relação é essa?

GARINGER, D. Textbook Evaluation. TEFL Web Journal. 2001. Disponível em: http://www.telfweb-j.org/ vlnl/garinger.html. Acesso em: 22/10/2004.

. Textbook Selection for the ESL Classroom. CAL-Center For Applied Linguistics. 2002. Disponível em: http://www.cal.org/resources/digest/0210garinger.html. Acesso em: 27/03/2005.

MENEGAZZO, R.E. \& XAVIER, R.P. (2004). Do método à autonomia do fazer crítico. Trabalhos em Lingüística Aplicada, v.43, n.1, p.115-126.

NUNAN, D. (1988). Syllabus Design. Oxford: Oxford University Press.

PRABHU, N.S. (1990). There is no best method - Why?. TESOL Quarterly, v. 24, n.2, p.161-176.

RICHARDS, J. The role of textbooks in language programs. (s/d) Disponível em: (www.professorjackrichards.com/pdfs/role-of-textbooks.pdf). Acesso em: 20/09/2004.

ROCHA, H. V.; OEIRAS, J.Y.Y. \& ALMEIDA FILHO, J.C.P. Fundamentos para um ambiente computacional para o Ensino à Distância de Língua Estrangeira. In: Anais do VII Simpósio Brasileiro de Informática na Educação. São José dos Campos, São Paulo. 1998. Disponível em: http://teleduc.nied.unicamp.br/pagina/ index.php. Acesso em: 03/11/04.

UR, P. (1991). A Course in Language Teaching: Practice and Theory. Cambridge: Cambridge University Press. 


\section{ANEXO I}

\section{Prezado Professor,}

Estou realizando um estudo sobre o Livro Didático de Inglês para a minha monografia no Curso de Especialização em Metodologia do Ensino da Língua Inglesa na UNOESC Joaçaba. As informações a serem coletadas neste questionário dependem de sua atenção, sinceridade e clareza às respostas. Sua identidade será preservada em sigilo, pois o que interessa a este trabalho, é o conjunto de dados e a compreensão das informações para conhecer o papel do livro didático de inglês no contexto escolar. Conto, portanto, com a sua contribuição para o aprofundamento deste assunto.

\section{Primeiro nome:}

2. Telefone para contato:

3. Data de nascimento:

4. Número de anos atuando como professor de inglês:

5. Instituição onde você trabalha atualmente:

( ) escola de idiomas

( ) escola do ensino fundamental e/ou médio

( ) outro (especifique):

6. Sistema de ensino no qual você trabalha atualmente:

( ) público

( ) particular

7. Formação acadêmica:

( ) Licenciatura em Letras - Português e Inglês.

( ) Licenciatura em

( ) Bacharelado em

( ) Especialização em

( ) Mestrado em

( ) Doutorado em

( ) Não tenho formação universitária. 
XAVIER \& URIO - O professor de inglês e o livro didático: que relação é essa?

8. Assinale os 4 (quatro) recursos didático-pedagógicos indispensáveis para o trabalho do professor de inglês:

( ) Aparelho de som

( ) TV e vídeo cassete

( ) Computador conectado à internet

( ) Máquina fotocopiadora

( ) Quadro de giz

9. O que representa o livro didático para você?

Para mim o livro didático é

10. Em suas aulas você...

( ) adota livro didático previamente escolhido por você.

( ) adota livro didático determinado pela escola.

( ) adota apostila determinada pela escola.

( ) adota apostila elaborada por você.

( ) não adota nenhum livro ou apostila.

( ) Outro (especifique):

11. Em caso de você não adotar livro didático ou apostila, como você organiza suas atividades de ensino?

( ) Utilizo atividades e textos de vários livros didáticos.

( ) Utilizo atividades e textos de um único livro didático.

( ) Crio minhas próprias atividades de ensino.

( ) Utilizo atividades e textos oferecidos na Internet.

( ) Outro (especifique):

12. Em caso de você adotar livro didático ou apostila, responda:

a) Qual é o nome completo do livro didático ou apostila que você adota?

b) Por que razão você ou a escola adotou este livro em particular?

13. Em geral, você vê algum ponto positivo ou negativo nos livros didáticos de inglês? PONTOS POSITIVOS: PONTOS NEGATIVOS: 
14. Em sua opinião, o que deve ter um livro didático para ser considerado bom ou ótimo? Justifique sua resposta.

15. Que elementos você considera importante na escolha de um livro didático de inglês para ser adotado?

16. Ao usar um livro didático, você:

( ) procura seguir todas as atividades propostas.

( ) procura selecionar somente aquelas atividades que sejam de maior interesse para os alunos.

( ) procura adaptar algumas atividades.

( ) procura complementar o livro didático com atividades extras.

( ) procura complementar o livro didático com mais informações gramaticais, culturais, etc.

( ) Outro:

17. Em sua opinião, quais as vantagens e desvantagens de se usar ou adotar um livro didático?

\section{VANTAGENS:}

\section{DESVANTAGENS:}

18. O que você faz quando encontra textos ou atividades no livro didático que você não se simpatiza?

19. Dê a sua opinião sobre as questões abaixo e justifique.

a) Os livros didáticos de língua inglesa publicados por editoras internacionais são melhores que os livros didáticos de inglês de editoras nacionais.
( ) Concordo.
( ) Não concordo.
( ) Concordo em termos.

Justifique:

b) Os livros didáticos de língua inglesa, em geral, contribuem para a formação de estudantes mais participativos e críticos na sociedade.
( ) Concordo.
( ) Não concordo.
( ) Concordo em termos.

Justifique: 
XAVIER \& URIO - O professor de inglês e o livro didático: que relação é essa?

c) A maioria dos livros didáticos de língua inglesa atendem às necessidades dos nossos professores e alunos.
( ) Concordo.
( ) Não concordo.
( ) Concordo em termos.

Justifique:

20. Você costuma usar o livro do professor, isto é, seguir suas orientações?
( ) Às vezes.
( ) Raramente.
( ) Sempre.
( ) Nunca.

21. Que orientação(ões) você costuma seguir no livro do professor?

( ) Não costumo seguir as orientações no livro do professor.

( ) Costumo seguir as orientações metodológicas (de como abordar o assunto, os exercícios, como corrigi-los).

( ) Costumo seguir as orientações de como avaliar os alunos.

( ) Costumo seguir as sugestões de atividades extras.

( ) Costumo consultar o gabarito dos exercícios e atividades.

( ) Costumo ler as informações teórico-metodológicas.

( ) Costumo ler a bibliografia para leitura complementar.

( ) Outro:

22. Que informação(ões) você considera necessária e desnecessária em um manual de ensino?

NECESSÁRIA:

DESNECESSÁRIA: 